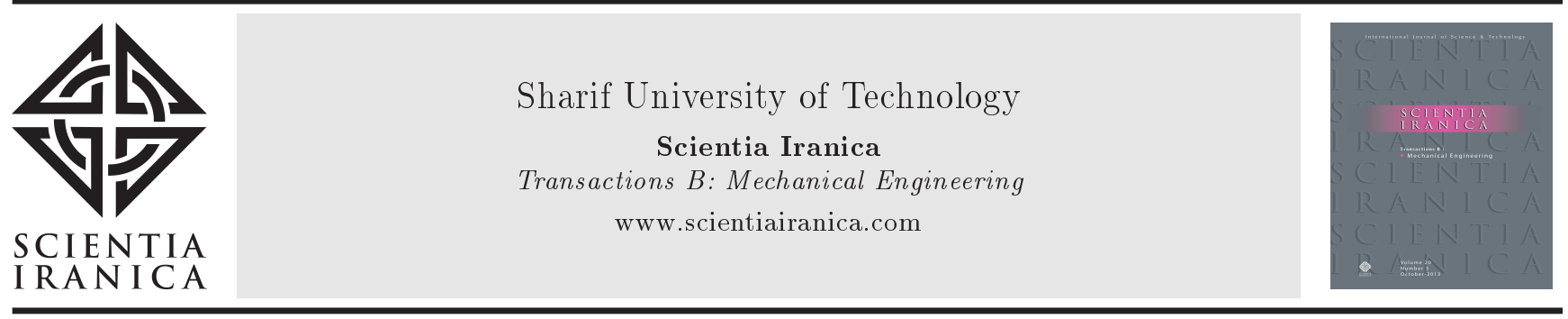

\title{
Effects of non-equilibrium condensation on aerodynamics of the flow field in a steam turbine cascade
}

\author{
H. Bagheri-Esfe ${ }^{a}$, M.J. Kermani ${ }^{b}$ and M. Saffar-Avval ${ }^{b, *}$ \\ a. Faculty of Engineering, University of Shahreza, Shahreza, P.O. Box 86149-56841, Iran. \\ b. Department of Mechanical Engineering, Amirkabir University of Technology, Tehran, P.O. Box 15875- 4413, Iran.
}

Received 7 April 2015; received in revised form 26 February 2016; accepted 16 April 2016

KEYWORDS
Steam turbine;
Non-equilibrium
condensation;
Deviation angle;
Stagnation pressure
loss.

\section{Introduction}

In a steam power plant, power is extracted from expanding steam in three stages, namely High Pressure (HP), Intermediate Pressure (IP), and Low Pressure (LP) turbines. During the expansion process in the LP turbine, the steam cools down; at some stages, droplet nucleation occurred and a two-phase vaporliquid mixture appeared. Wet stages in the steam turbines are less efficient compared to those running with superheated vapor.

The study of low-pressure turbine stages is of particular interest, since they produce the largest portion of the power (across all of the stages), and yet are

\footnotetext{
*. Corresponding author. Tel.: +98 2164543423 ;

E-mail address: mavval@aut.ac.ir (M. Saffar-Avval)

\begin{abstract}
In the present paper, an in-house CFD code is developed using Roe scheme to outlet pressures. Firstly, comparison is performed between results of wet and dry outhow direction, and consequently the flow entering to the next blade deviates from stagnation pressure loss and entropy generation due to non-equilibrium condensation
\end{abstract} (C) 2017 Sharif University of Technology. All rights reserved. susceptible to additional losses due to the presence of a second liquid phase [1]. Thermodynamic irreversible losses, generated with non-equilibrium conditions, are significant at low-pressure stages, since the efficiency is reduced by approximately $1 \%$ for every additional percent of wetness [2]. On the other hand, condensation can cause some permanent damages, like mechanical erosions on the blade surface.

In the tip section of the last stages of steam turbines, complicated phenomena could be observed due to high velocity and excessive expansion rate of the flow. Firstly, formation of shock and expansion waves at the trailing edge can affect the behavior of the flow field. On the other hand, when the flow reaches a specified supercooling degree, suddenly nucleates and condensation shock are formed in the supersonic flow. The condensation shock and attendance of the liquid 
phase can change the flow properties in the turbine stage; then, aerodynamics of the flow field with respect to dry flow can vary completely.

Research studies on the low-pressure turbine stages have great importance due to widespread usage of the steam turbines for power generation. Commence of wide studies in two-phase vapor-liquid flows dates back to the 1970s when Mcdonald [3] presented the theory of homogeneous nucleation. He studied this phenomenon in two thermodynamic and kinetic aspects.

In the next years, some experimental and numerical results related to two-phase condensing flows were presented. Moore et al. [4] performed one of the earliest experiments related to condensation in nozzles. Then, some experiments were performed on a cascade of turbine to study the phenomena associated with spontaneous condensation by Skillings $[5,6]$. He studied the effects of inlet superheating and outlet Mach number on the trailing edge shock structure. Bakhtar et al. [7-9] carried out some experiments to study two-phase nucleating steam flow in a blade passage. Also, they performed a comparative study of the treatment of two-dimensional nucleating flows using Runge-Kutta and Denton's methods [10].

In 1984, Young [11] presented a theoretical investigation of chocking in steady, one-dimensional, non-equilibrium wet steam in the nozzles. Then, he presented a method to solve the governing equations of wet steam flow in two and quasi-three dimensional turbine cascades [12]. The mixture conservation equations were solved in a Eulerian reference frame, and droplet phase was computed by integrating the relevant equations along true streamlines in a Lagrangian reference frame. White and Young [13] presented a timemarching method to predict unsteady phenomena in condensing steam flows. In 2000, White [14] developed a numerical method for the prediction of condensing steam flow within compressible boundary layers. Then, White and Hounslow [15] presented a new method for modeling droplet size distributions within condensing steam flows. Also, White [16] presented a comparison of modeling methods for polydispersed wet-steam flow.

In recent years, Gerber [17] used the classical theory of nucleation and proposed a new numerical model (Eulerian-Lagrangian) to solve the two-phase compressible flows in steam nozzles and turbine blades. Then, Gerber and Kermani [1] presented a pressurebased Eulerian-Eulerian multi-phase model for nonequilibrium condensation in transonic steam flow. In 2007, Gerber and Mousavi [18] investigated the effectiveness of the Quadrature Method Of Moments (QMOM) in representing droplet size distributions present in the low-pressure steam turbine stages. Halama et al. [19] used an in-house code for simulating two-phase condensing steam by adding Giles's matching algorithm using Lax-Wendroff method.
Single- and two-fluid models for steam condensing flow modeling were presented by Dykas and Wroblewki [20]. In 2012, they presented the computational results of the wet steam flow through the Laval nozzles for low and high inlet pressures [21]. Also, an effective method of determination of water vapor properties was presented in the case of expansion in the nozzle at high pressures. Recently, Hamidi and Kermani [22] investigated numerical solution of a compressible two-phase two-component moist-air flow with and without shock waves. They used the equilibrium thermodynamic model to study the condensation in a one-dimensional nozzle.

In 2016, Bagheri-Esfe et al. investigated effects of non-equilibrium condensation on deviation angle and efficiency in a steam turbine stage [23]. Also, they studied effects of surface roughness on deviation angle and performance losses in wet steam turbines [24].

According to the literature review, it is concluded that several research studies have been conducted to simulate two-phase condensing flows using different numerical methods. But, few researchers have investigated effects of non-equilibrium condensation on aerodynamics of the flow field in the steam turbines.

In the present paper, an in-house CFD code is developed using Roe scheme to simulate condensing two-phase flow. Effects of condensation on aerodynamics and different specifications of the cascade flow field are investigated for various outlet pressures. Also, the mechanism of flow deviation in the cascade flow field is described. This study gives a practical understanding of the condensation effects on the performance of steam turbine stages operating at subsonic/supersonic flow regimes.

\section{Governing equations}

Assumptions used in the present study of the twophase flow are as follows: Slip velocity between droplets and vapor is ignored due to infinitesimal radius of the droplets, condensation is homogenous, and condensing steam flow is assumed to be adiabatic and inviscid.

In transonic two-phase flows passing around the steam turbine blades, contribution of the viscous losses is negligible in comparison to other loss sources (aerodynamic and thermodynamic losses). Hence, utilization of inviscid solvers is accurate enough to simulate transonic two-phase flows in the steam turbines [23].

Two-dimensional governing equations consist of Euler equations for the mixture and transport equations for parameters of droplet spectra $\left(Q_{0}, Q_{1}\right.$, and $Q_{2}$ ) and are shown in full conservative form as [25]:

$$
\partial_{t} W+\partial_{x} F+\partial_{y} G=S,
$$

where $W$ is the conservative vector, $F$ and $G$ denote the 
horizontal and vertical flux vectors, respectively, and $S$ is the source term. These parameters are calculated as follows:

$$
\begin{aligned}
W= & {\left[\rho, \rho u, \rho v, \rho e_{t}, \rho \chi, \rho Q_{2}, \rho Q_{1}, \rho Q_{0}\right]^{T}, } \\
F= & {\left[\rho u, \rho u^{2}\right.} \\
& \left.+P, \rho u v, \rho u e_{t}, \rho u \chi, \rho u Q_{2}, \rho u Q_{1}, \rho u Q_{0}\right]^{T}, \\
G= & {\left[\rho v, \rho v u, \rho v^{2}\right.} \\
& \left.+P, \rho v e_{t}, \rho v \chi, \rho v Q_{2}, \rho v Q_{1}, \rho v Q_{0}\right]^{T}, \\
& \\
S= & {\left[0,0,0,0, \frac{4}{3} \pi r_{c}^{3} \rho_{l} \mathrm{~J}+4 \pi \rho Q_{2} \dot{r} \rho_{l}, r_{c}^{2} \mathrm{~J}\right.} \\
& \left.+2 \rho Q_{1} \dot{r}, r_{c} \mathrm{~J}+Q_{0} \rho \dot{r}, \mathrm{~J}\right]^{T},
\end{aligned}
$$

where $P, e_{t}$, and $\chi$ are pressure, total energy per unit volume, and wetness fraction, respectively. Also, $\rho$ denotes the mixture density; $u$ and $v$ are velocity components for both vapor and liquid.

The Hill's moments are defined as follows [26]:

$$
\begin{aligned}
& Q_{0}=N, \quad Q_{1}=\sum_{i=1}^{N} r_{i}, \quad Q_{2}=\sum_{i=1}^{N} r_{i}^{2}, \\
& r= \begin{cases}0, & \chi \leq 10^{-6} \\
\sqrt{Q_{2} / Q_{0}}, & \chi>10^{-6}\end{cases}
\end{aligned}
$$

with $r$ denoting the average radius, $r_{i}$ the radius of $i$ th droplet, and $N$ total number of droplets per unit mass of mixture. The limit value $10^{-6}$ is chosen to stabilize the numerical algorithm [25].

Based on the classical homogeneous nucleation theory, the number $\mathrm{J}$ of new condensed droplets per unit volume and per second is computed as [27]:

$$
\begin{aligned}
& \mathrm{J}=\frac{J_{c l}}{1+\phi}, \quad \phi=\frac{2(\gamma-1)}{(\gamma+1)} \frac{h_{f g}}{R_{v} T_{v}}\left[\frac{h_{f g}}{R_{v} T_{v}}-\frac{1}{2}\right], \\
& J_{c l}=\sqrt{\frac{2 \sigma}{\pi m_{v}^{3}}} \cdot \frac{\rho_{v}^{2}}{\rho_{l}} \cdot \exp \left(-\frac{4 \pi r_{c}^{2} \sigma}{3 k_{B} T_{v}}\right), \\
& r_{c}=\frac{2 \sigma}{\rho_{l} R_{v} T_{v} \ln \left(P / P_{S}\right)}
\end{aligned}
$$

where $\phi, h_{f g}$, and $\gamma$ are correction parameter, latent heat of evaporation, and specific heat ratio of the vapor, respectively. $m_{v}$ is molecular weight of the vapor and $\sigma$ is surface tension. In Eq. (5), $k_{B}, r_{c}$, and $P_{S}$ denote the Boltzmann constant, critical radius, and saturation pressure, respectively. In Eq. (2), radius growth rate is obtained by [28]:

$$
\begin{aligned}
\dot{r} & =\frac{P}{h_{f g} \rho_{l} \sqrt{2 \pi R_{v} T_{v}}} \cdot \frac{\gamma+1}{2 \gamma} \cdot c_{p}\left(T_{l}-T_{v}\right), \\
T_{l} & =T_{S}-\frac{2 \sigma T_{S}}{h_{f g} \rho_{l} r},
\end{aligned}
$$

where $T_{l}$ and $T_{S}$ denote droplet and saturation temperatures, respectively. For the present low pressure computation, the ideal gas equation of state has sufficient accuracy. Hence:

$$
P=\rho_{v} R_{v} T_{v}=(1-\chi) \rho R_{v} T_{v} .
$$

In this paper, the entropy of mixture is computed as follows:

$$
s=\left(c_{p} \ln T_{v}-R_{v} \ln P\right)-\left(\frac{\chi h_{f g}}{T_{v}}\right),
$$

where $c_{p}$ is specific heat capacity at constant pressure.

Different properties of the vapor and liquid (e.g., internal energy, and enthalpy) are determined using empirical equations [27].

\section{Numerical discretization}

As shown in Eqs. (1) and (2), the governing equations consist of Euler equations for the mixture and four additional equations for the droplets. Eq. (1) is written in generalized coordinates as follows:

$$
\frac{\partial W_{1}}{\partial t}+\frac{\partial F_{1}}{\partial \xi}+\frac{\partial G_{1}}{\partial \eta}=S_{1}
$$

The conservative and flux vectors in generalized coordinates can be connected to those in physical space using:

$$
\begin{array}{ll}
W_{1}=\frac{W}{J}, & F_{1}=\frac{\xi_{x}}{J} F+\frac{\xi_{y}}{J} G, \\
G_{1}=\frac{\eta_{x}}{J} F+\frac{\eta_{y}}{J} G, & S_{1}=\frac{S}{J},
\end{array}
$$

in which $\xi_{x}, \xi_{y}, \eta_{x}$, and $\eta_{y}$ are metrics, and $J$ is the Jacobian of transformation.

\subsection{Temporal discretization}

Using a forward Euler scheme for the time derivative, Eq. (10) is written in a semi-discrete form as:

$$
\frac{W_{1}^{n+1}-W_{1}^{n}}{\Delta t}+\left(\frac{\partial F_{1}}{\partial \xi}\right)^{n}+\left(\frac{\partial G_{1}}{\partial \eta}\right)^{n}=S_{1}^{n} .
$$

The value of $W_{1}^{n+1}$ is obtained from Eq. (12), then the primitive variables $\left(\rho, u, v, e_{t}\right)$ at the new time step $(n+$ 1 ) will be determined. Since this equation is explicit in time, stability of the solution is governed by the $\mathrm{CFL}$ condition [29]. 


\subsection{Spatial discretization}

In the Roe scheme, the inner and outer flow conditions are determined using either the first, second, or thirdorder upwind biased algorithm. Extrapolation of the primitive variables, such as pressure, velocity, and temperature from the cell centers to the cell faces, is performed by the MUSCL strategy [30]. To determine the variables at the east face of the control volume $(E)$, the following relations are used:

$$
\begin{aligned}
& q_{E}^{L}=q_{i, j}+\frac{1}{4}\left[(1-\kappa) \Delta_{W} q+(1+\kappa) \Delta_{E} q\right], \\
& q_{E}^{R}=q_{i+1, j}-\frac{1}{4}\left[(1-\kappa) \Delta_{E E} q+(1+\kappa) \Delta_{E} q\right],
\end{aligned}
$$

where $L$ and $R$ denote the left and right sides of each cell face, as shown in Figure 1; and $q$ represents either of the four primitive variables, i.e. $q \in\{P, T, u, v\}$. Also, $\kappa=1$ and $1 / 3$ correspond, respectively, to the second order and the third order upwind-biased algorithms. In Eq. (13), $\Delta_{W} q=q_{i, j}-q_{i-1, j}, \Delta_{E} q=q_{i+1, j}-q_{i, j}$, and $\Delta_{E E} q=q_{i+2, j}-q_{i+1, j}$. For the first order algorithm, $L$ and $R$ side values of the primitive variables at the $E$-face are determined from: $q_{E}^{L}=q_{i, j}$ and $q_{E}^{R}=q_{i+1, j}$. A similar formula can be written for the inner $(L)$ and outer $(R)$ values at the north face of the control volume.

The van Albada flux limiter is used for damping the spurious numerical oscillations in high resolution computations, written as [31]:

$$
\begin{aligned}
& q_{E}^{L}=q_{i, j}+\frac{\phi}{4}\left[(1-\kappa) \Delta_{W} q+(1+\kappa) \Delta_{E} q\right] \\
& q_{E}^{R}=q_{i+1, j}-\frac{\phi}{4}\left[(1-\kappa) \Delta_{E E} q+(1+\kappa) \Delta_{E} q\right] .
\end{aligned}
$$

The limiter function $\phi$ is defined by:

$$
\phi_{i, j}=\frac{2\left(\Delta_{W} q\right)\left(\Delta_{E} q\right)+\delta}{\left(\Delta_{W} q\right)^{2}+\left(\Delta_{E} q\right)^{2}+\delta},
$$

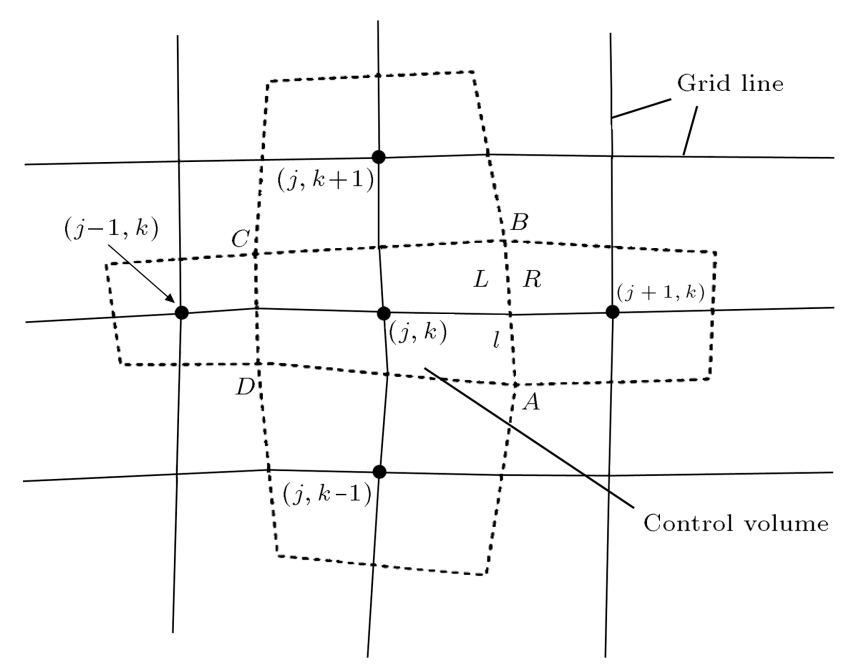

Figure 1. Arbitrary configuration of grid lines with the corresponding cell-vertex control volume allocated to each node. where $\delta$ is a small value for preventing indeterminacy in regions of uniform flow, i.e., in and around $\Delta_{W} q=$ $\Delta_{E} q=0$.

An entropy correction method is used to avoid expansion shocks in the regions where the eigenvalues become equal to zero. The relevant equation is written as:

$$
\begin{aligned}
& \hat{\lambda}_{\text {new }}=\frac{\hat{\lambda}^{2}+\varepsilon^{2}}{2 \varepsilon}, \quad|\lambda|<\varepsilon, \\
& \varepsilon=4 \max \left[0,\left(\hat{\lambda}-\lambda^{L}\right),\left(\lambda^{R}-\hat{\lambda}\right)\right],
\end{aligned}
$$

where $\lambda^{L}$ and $\lambda^{R}$ are the eigenvalues determined at the inner and outer flow conditions, respectively. Also, $\hat{\lambda}$ is the eigenvalue of the flux Jacobian matrix determined at Roe's averaged condition [32].

The numerical flux using Roe scheme is obtained from the following formulae:

East face:

$$
F_{E}=\frac{1}{2}\left(F_{E}^{L}+F_{E}^{R}\right)-\frac{1}{2} \sum_{k=1}^{4}\left|\hat{\lambda}_{E}^{(k)}\right| \delta w_{E}^{(k)} \hat{T}_{E}^{(k)} .
$$

North face:

$$
G_{N}=\frac{1}{2}\left(G_{N}^{L}+G_{N}^{R}\right)-\frac{1}{2} \sum_{k=1}^{4}\left|\hat{\lambda}_{N}^{(k)}\right| \delta w_{N}^{(k)} \hat{T}_{N}^{(k)},
$$

where $\lambda$ is the eigenvalue of the flux Jacobian matrix, $T$ is the corresponding eigenvector, and $\delta w$ is the wave amplitude vector. More details of Eqs. (17) and (18) can be found in [33].

\section{Results and discussion}

The geometry under study is a rotor tip section of a steam turbine, taken from [34]. Figure 2 shows this geometry and computational domain between blades. The blade section has a very large stagger $(\Gamma)$ of $63.27^{\circ}$. Chord length of the blade $(C)$ and pitch length of the cascade $(p)$ are equal to $43 \mathrm{~mm}$ and $37 \mathrm{~mm}$, respectively. Also, the inlet flow angle $(\beta)$ is $-38^{\circ}$. Moreover, inflow stagnation pressure and temperature are set to $99 \mathrm{kPa}$ and $382 \mathrm{~K}$, respectively. As shown in Figure 3, size of the grid is specified as $498 \times 65$ after grid-independency test. This grid is used for numerical simulation and illustrated in Figure 4 with the close-up near the leading and trailing edges.

\subsection{Validation}

To validate the present in-house code, the experimental data reported by Bakhtar and Mahpeykar [7] have been used. The boundary conditions for the current numerical simulation have been chosen as identical to those in the experimental test, such as the inflow direction $(\beta)$ is $-38^{\circ}$ and the inflow stagnation pressure 


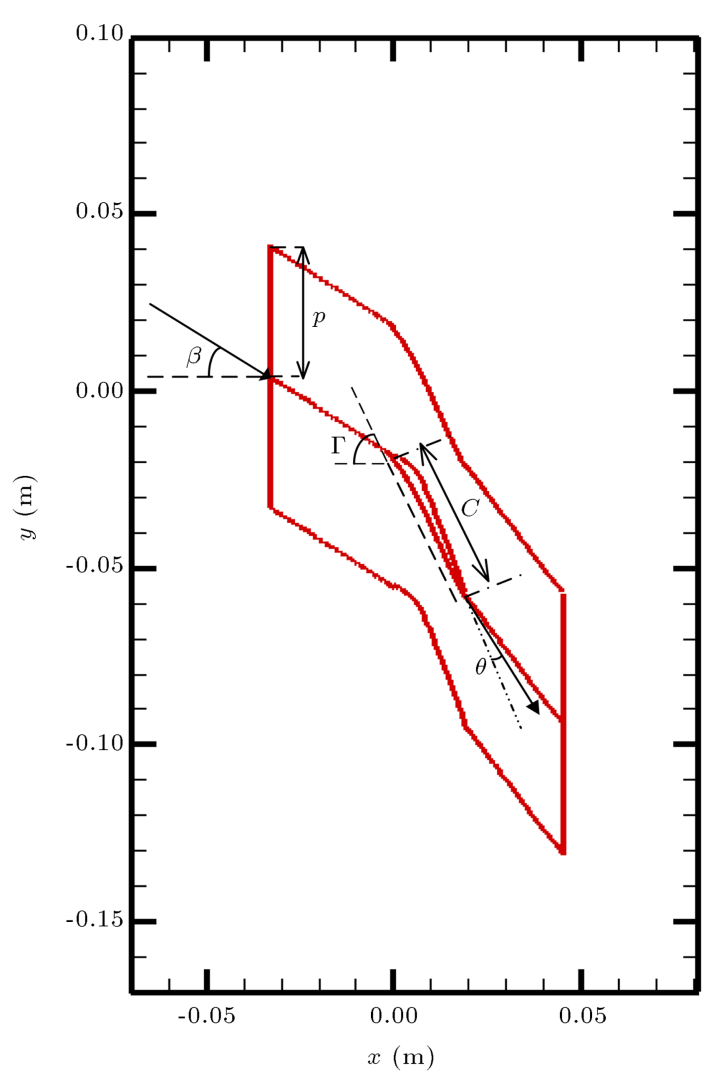

Figure 2. Geometry of the rotor-tip section and the computational domain [34], where $p$ is pitch length, $C$ is chord length, $\beta$ is flow angle at the entrance, $\Gamma$ is stagger angle, and $\theta$ is deviation angle.

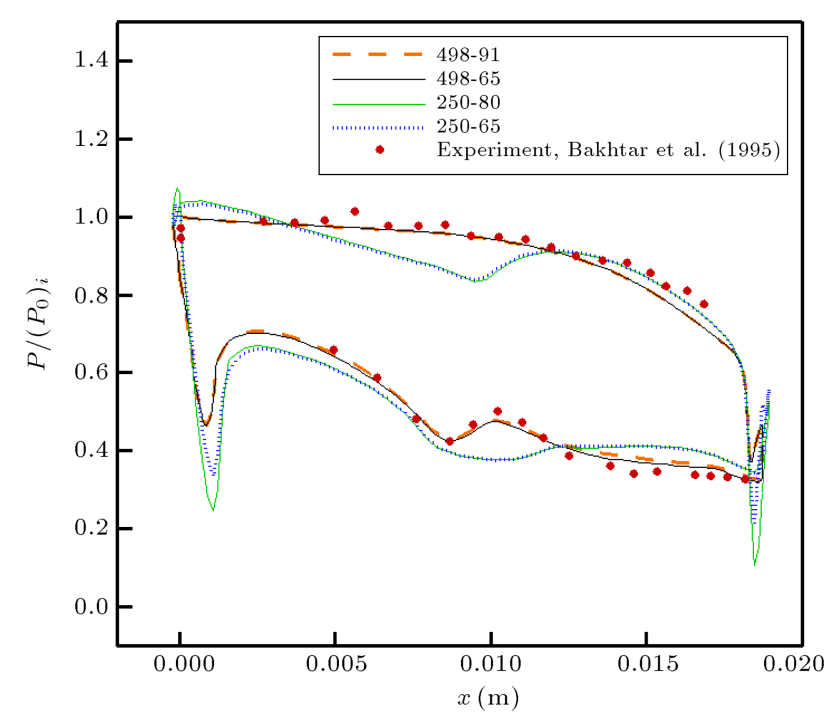

Figure 3. Grid independency test: Distribution of pressure ratio $\left(P / P_{0 i}\right)$ on the blade surface.

and temperature are set to $99.9 \mathrm{kPa}$ and $360.8 \mathrm{~K}$, respectively. At the inlet section, the wetness fraction $\chi=0$; at the outlet section, the back-pressure $P_{b}=42.7 \mathrm{kPa}$. Comparison of the pressure ratio on the suction and pressure surfaces between numerical

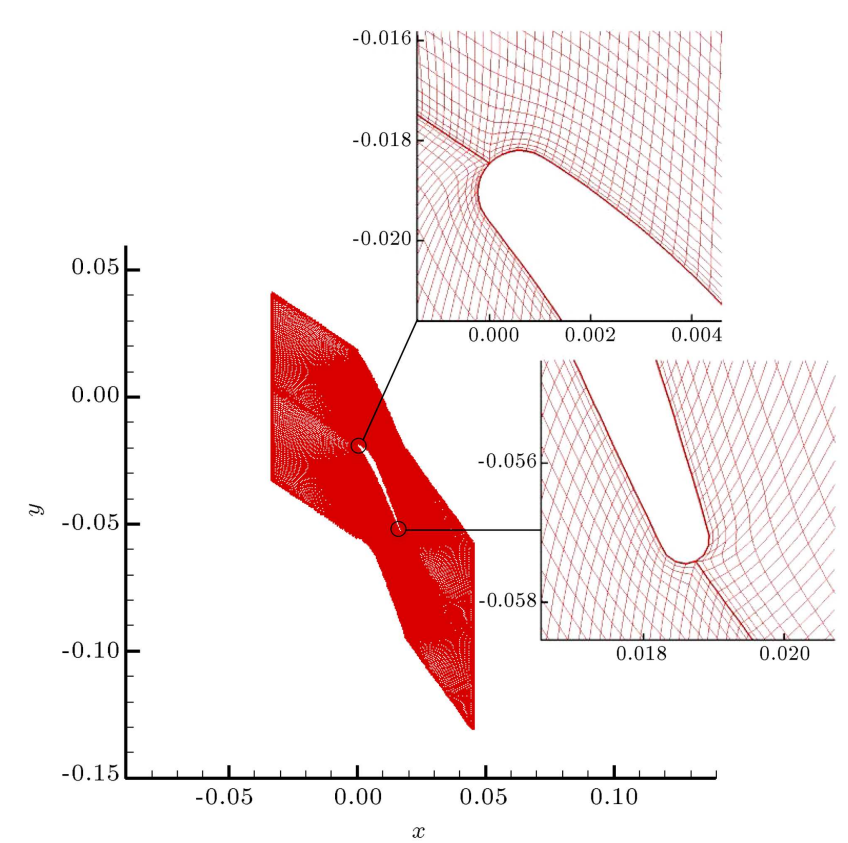

Figure 4. Grid used for numerical simulation $(498 \times 65)$ with the close-up near the leading and trailing edges.

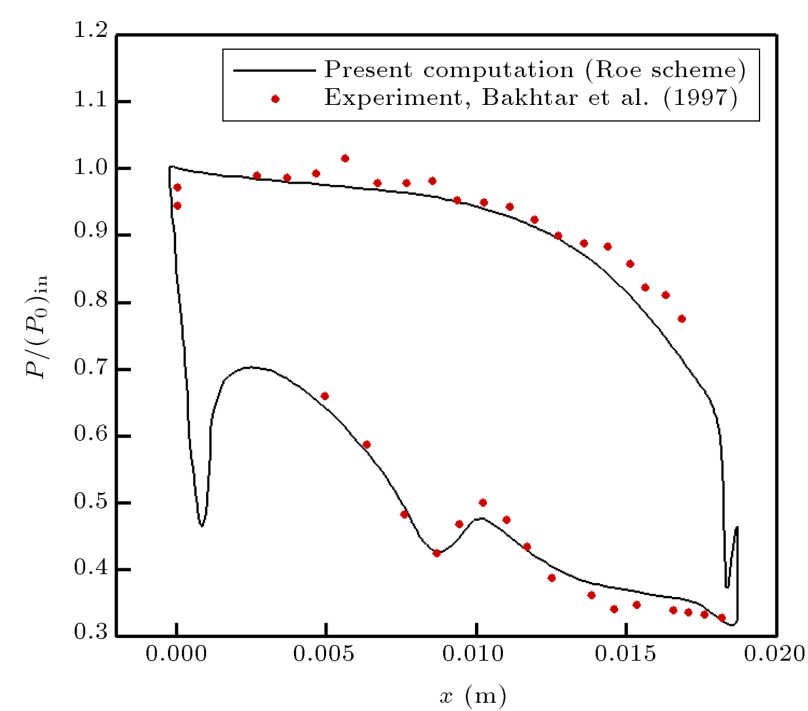

Figure 5. Validation: Comparison between numerical and experimental results [7]; distribution of pressure ratio on the pressure and suction surfaces. The present computation is performed with grid size of $498 \times 65$.

and experimental results is shown in Figure 5. As observed in this figure, good agreement exists between the results, and position of the condensation shock is captured well.

\subsection{Comparison between wet and dry cases}

According to the numerical results, characteristics of the flow (such as pressure and Mach number) are almost identical for the wet and dry cases, when the flow in the passage is subsonic. Also, the value of mass flow rate related to $P_{b}=60 \mathrm{kPa}$ (subsonic outflow) 
for dry and wet cases is determined as $1.95 \mathrm{~kg} / \mathrm{s}$ and $1.944 \mathrm{~kg} / \mathrm{s}$, respectively, with the difference between them being less than $0.4 \%$.

Flow passing through the blade passage can be modeled by a converging-diverging nozzle as shown in Figure 6. The convergent part of the nozzle consists of a passage taken from pressure surface (line DE) and some parts of suction surface (line AB), while the divergent part of the nozzle consists of the trailing edge streamline (line EF) and some parts of the suction surface (line $\mathrm{BC})$. Because some parts of the suction surface (BC) are located in the divergent part of the nozzle, this surface has more expansion rate in comparison to the pressure surface. Thus, condensation rate and wetness fraction near the suction surface are more than pressure surface. The flow passing through the divergent section of the blade experiences large expansion rate; thus, in the supersonic outflow cases, an oblique shock is formed at the trailing edge of the blade to match the outlet pressure.

For better understanding of the deviation angle, we consider two separate streamlines near the blade surface (Figure 7). As shown in this figure, the streamlines $a-b$ and $c-d$ pass near the suction and pressure surfaces, respectively. They have the same value of stagnation pressure at inlet boundary, namely $\left(P_{0}\right)_{\text {in }}$, but their stagnation pressure value differs at the trailing edge. Flow direction at the trailing edge of the blade depends on the values of $\left(P_{0}\right)_{e, s}$ and $\left(P_{0}\right)_{e, p}$ (stagnation pressure at the trailing edge near the suction and pressure surfaces). As shown in Figure 8(a), flow passes tangent to the camber line at the trailing edge when $\left(P_{0}\right)_{e, s}=\left(P_{0}\right)_{e, p}$. In the steam turbines, flow over the suction side experiences further stagnation pressure losses with respect to that of the pressure side, as it passes a sequence of condensationand aerodynamic-shocks over the suction side; thus, $\left(P_{0}\right)_{e, s}<\left(P_{0}\right)_{e, p}$. In this condition, the stream line at

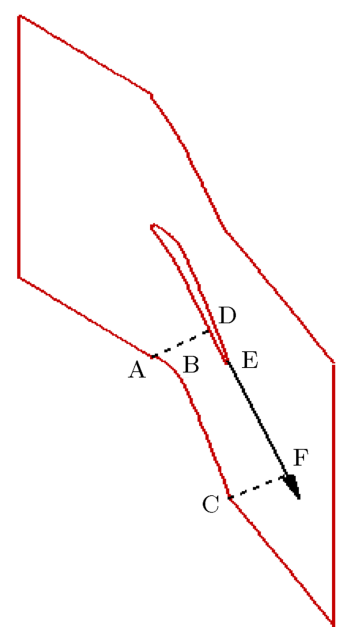

Figure 6. Schematic representation of converging-diverging nozzle in blade to blade domain.

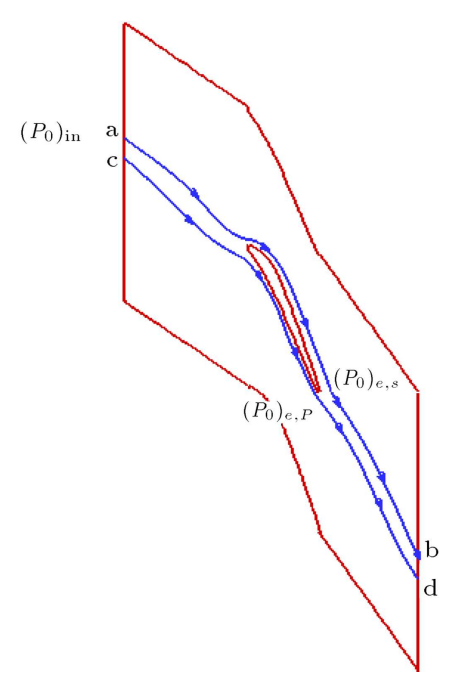

Figure 7. Representation of the streamlines near the blade surface.
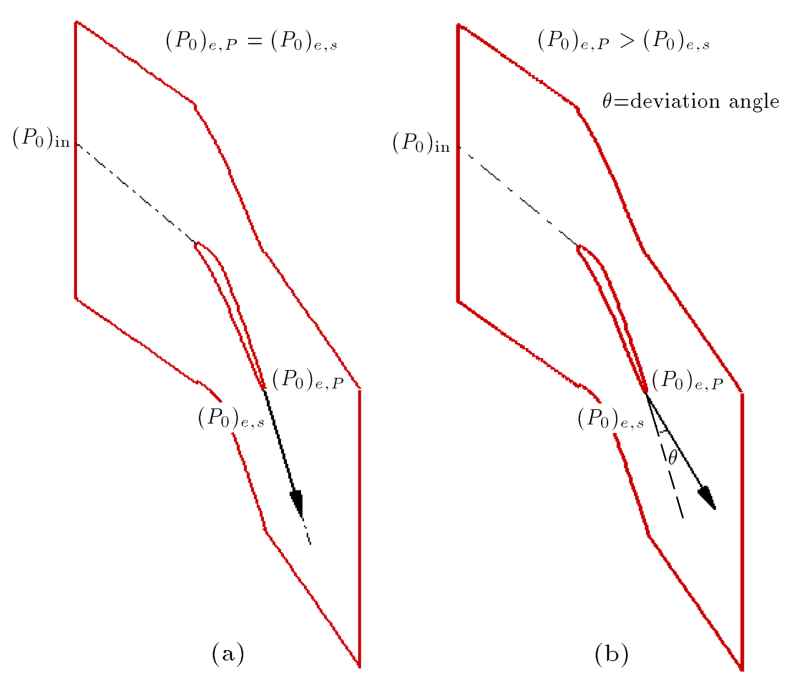

Figure 8. Different conditions for the flow direction at the trailing edge of the blade: (a) Flow passes tangent to the camber line at the trailing edge when $\left(P_{0}\right)_{e, s}=$ $\left(P_{0}\right)_{e, p}$, and (b) flow deviates at the trailing edge toward the suction surface when $\left(P_{0}\right)_{e, s}<\left(P_{0}\right)_{e, p}$.

the trailing edge turns toward the suction surface. In fact, this turning of the streamline at the trailing edge is called deviation angle (Figure 8(b)).

Comparison between results of wet and dry cases related to supersonic outflow $\left(P_{b}=30 \mathrm{kPa}\right)$ is shown in Figure 9 . In wet case, due to condensation and released latent heat, Mach number variation and flow expansion are less than dry case.

\subsection{Effects of outlet pressure variations on the flow field}

Figure 10 presents comparison of the results in the passage for different subsonic outlet pressures. As shown in Figure 10(a), expansion of flow near the suction surface is more noticeable than the pressure 
Supersonic outflow $\left(P_{b}=30 \mathrm{kPa}\right)$

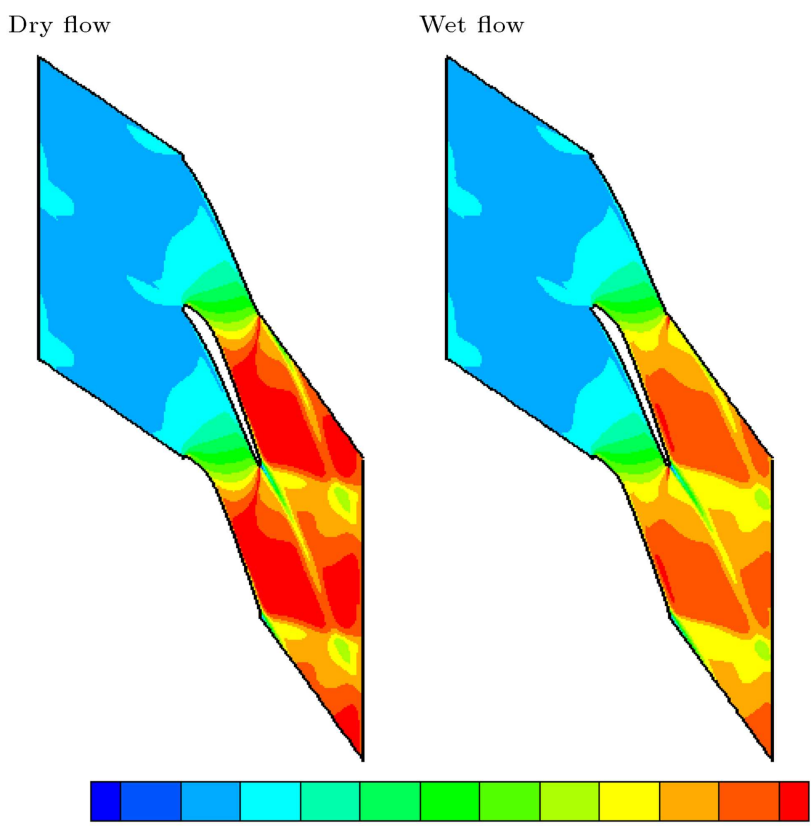

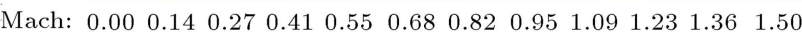

Figure 9. Comparison between results of wet and dry cases for supersonic outflow $\left(P_{b}=30 \mathrm{kPa}\right)$; Mach number contours.

surface. Hence, a supersonic pocket is formed near the maximum thickness over the suction surface. Also, reduction of the outlet pressure increases the size of the supersonic pocket formed on the suction surface. Contours of wetness fraction for subsonic outflows are illustrated in Figure 10(b). As observed in this figure, the value of wetness fraction close to the suction surface is more than pressure surface due to higher rate of flow expansion.

When flow in the passage is subsonic, information of outlet pressure reduction is propagated upstream. This information obligates upstream to increase the mass flow rate through the passage. Also, distribution of pressure, Mach number, and other flow characteristics in the passage varies. As shown in Figure 11, mass flow rate, $\dot{m}$, increases with exit Mach number $\left(M_{e}\right)$ in subsonic cases.

Comparison of contours in the passage between blades for different supersonic outlet pressures is illustrated in Figure 12. For the supersonic outlet cases, if the outlet pressure decreases, the flow field will change so that the outlet pressure is met. For these cases, eigenvalues of the flux Jacobian matrix are positive; thus, information is not propagated upstream of the flow. Hence, reduction of $M_{e}$ does not change the mass flow rate through the passage in supersonic outflow cases as shown in Figure 11.

For flow passing through a converging-diverging nozzle with heat transfer, the following can be shown [35]:

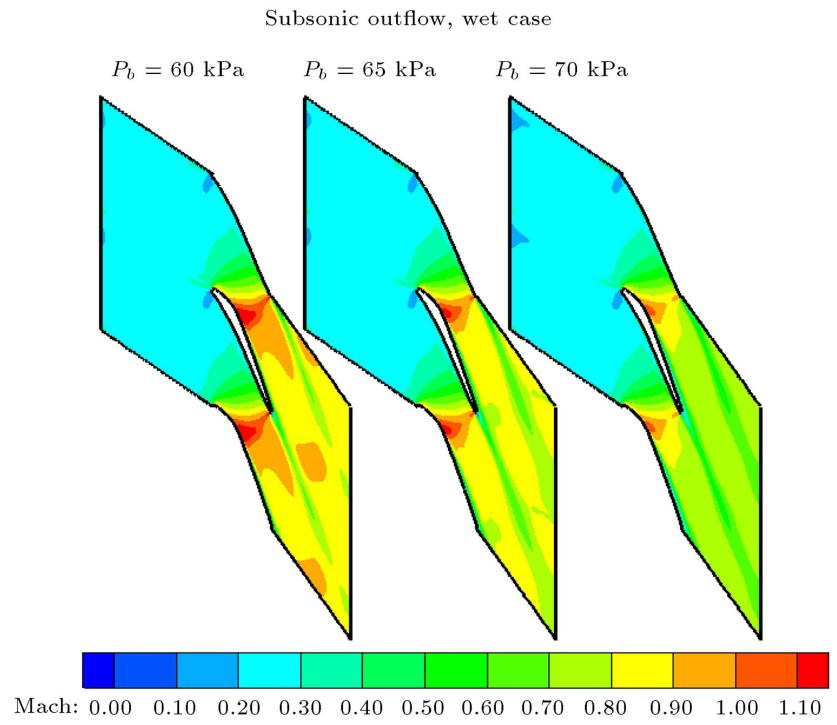

(a)

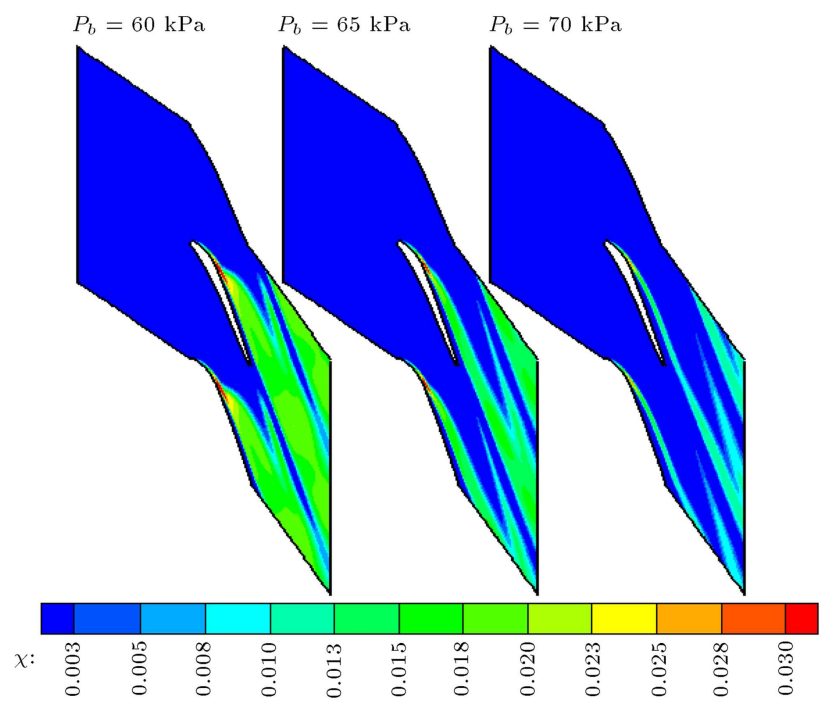

(b)

Figure 10. Comparison of contours in the passage for different subsonic outlet pressures: (a) Mach number contours, and (b) wetness fraction contours.

$$
-\frac{d A}{A}+\frac{\left(1+\gamma M^{2}\right) \times \frac{d q}{c_{p} T}}{2\left(1+\frac{\gamma-1}{2} M^{2}\right)}+\frac{\left(M^{2}-1\right) \times \frac{d M}{M}}{\left(1+\frac{\gamma-1}{2} M^{2}\right)}=0 .
$$

It is worthwhile to note that in the case of no heat transfer to the nozzle (i.e., $d q=0$ ), Eq. (19) is reduced to the isentropic flow equation in the nozzle. As pointed earlier, flow in the blade to blade passage can be simulated such as a nozzle (Figure 6). For $d q>0$, using Eq. (19), it is concluded that the sonic line $(M=1)$ occurs downstream of the throat (in the diverging portion of the nozzle where $d A>0$ ).

In the two-phase condensing flows, the latent heat is taken from a portion of the vapor that is going to condense and moves toward the vapor phase. Hence, it assumes that heat is supplied to the flow from external 


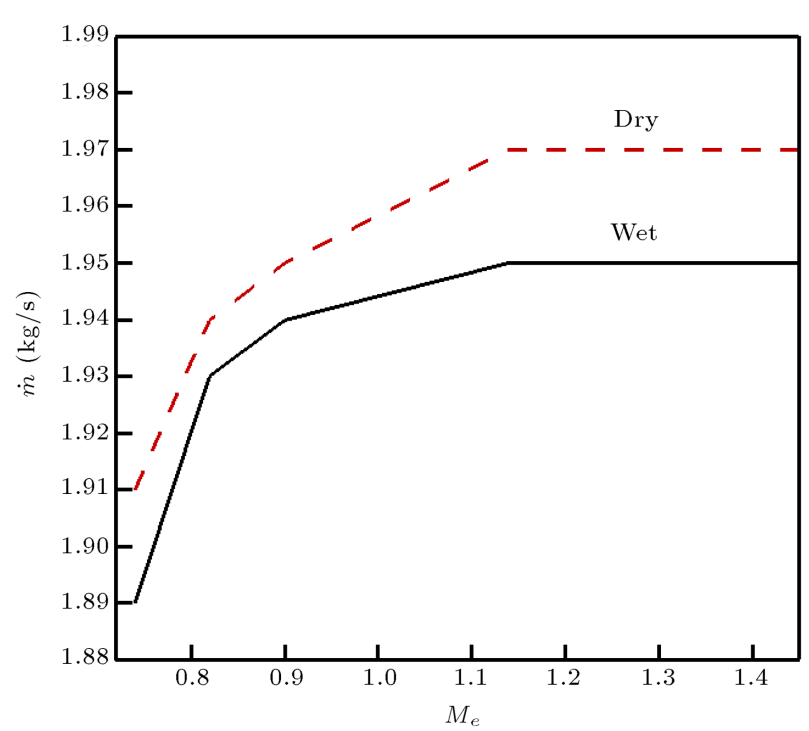

Figure 11. Variations of mass flow $(\dot{m})$ rate with exit Mach number $\left(M_{e}\right)$ for dry and wet cases.

sources and the sonic line appears downstream of the throat. This is illustrated in Figure 12(a). Also, according to Eq. (19), it can be seen that the Mach number distribution corresponds to the value of latent heat $(d q>0)$ and area variation $(d A)$ in the passage.

Position of the condensation shock formed on the suction surface is shown in Figure 12(b). Condensation shock is a rapid release of heat from a portion of vapor that is going to condense toward the core vapor. Hence, the core vapor experiences a rapid temperature rise like a shock. Just on this shock, condensation occurs and wetness fraction increases. This phenomenon occurs only in the supersonic region. Condensation shock has two important effects on the flow field. Firstly, pressure and temperature of the flow increase after this phenomenon; condensation shock changes the oblique shock angle formed at the trailing edge.

Sequence of condensation and evaporation phenomena over the suction side of the blade is depicted in Figure 12(b). As shown in this figure, wetness fraction decreases across the oblique shock due to evaporation of the droplets.

There are two important mechanisms for adapting the outlet pressure reduction in the supersonic outflows:

- Decrease in the oblique shock angle. When the outlet pressure decreases, the oblique shock becomes weaker and its angle reduces; thus, pressure increment of the flow across the oblique shock decreases;

- Increase in the divergence angle of the trailing edge streamline. This leads to increase in the expansion rate of the flow in the divergent portion of the passage.

Figure 13 illustrates situation of oblique shock and streamline at the trailing edge for different supersonic

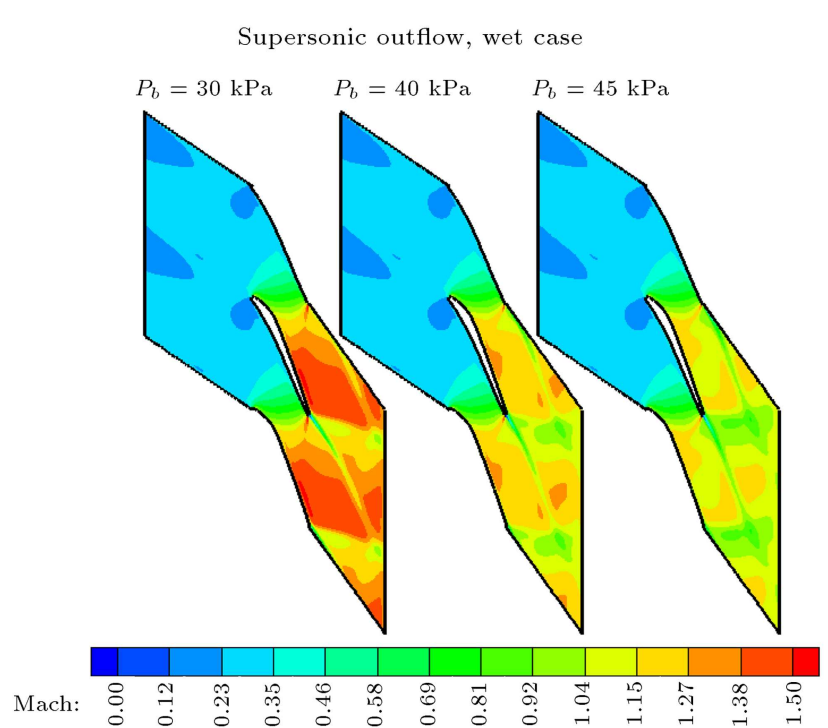

(a)

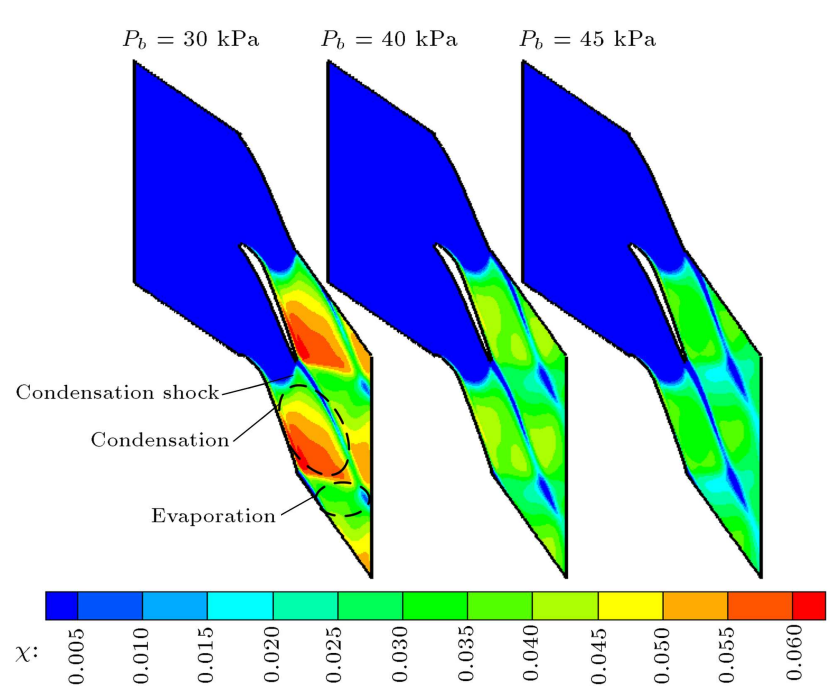

(b)

Figure 12. Comparison of contours in the passage for different supersonic outlet pressures: (a) Mach number contours, and (b) wetness fraction contours.

outlet pressures. As shown in this figure, reduction of back-pressure reduces the oblique shock angle and increases the divergence angle of the trailing edge streamline.

\subsection{Effects of condensation on the specifications of the flow field}

In the previous sections, effects of condensation on the pressure, Mach number, and wetness fraction contours in the flow field were investigated. Now, effects of this phenomenon on different specifications of the flow field are studied. Total pressure loss coefficient $(\omega)$, entropy generation $(\dot{\sigma})$, and deviation angle $(\theta)$ are three important parameters studied here for a better investigation of the condensation phenomenon. $\omega$ and $\dot{\sigma}$ are computed using the following equations: 


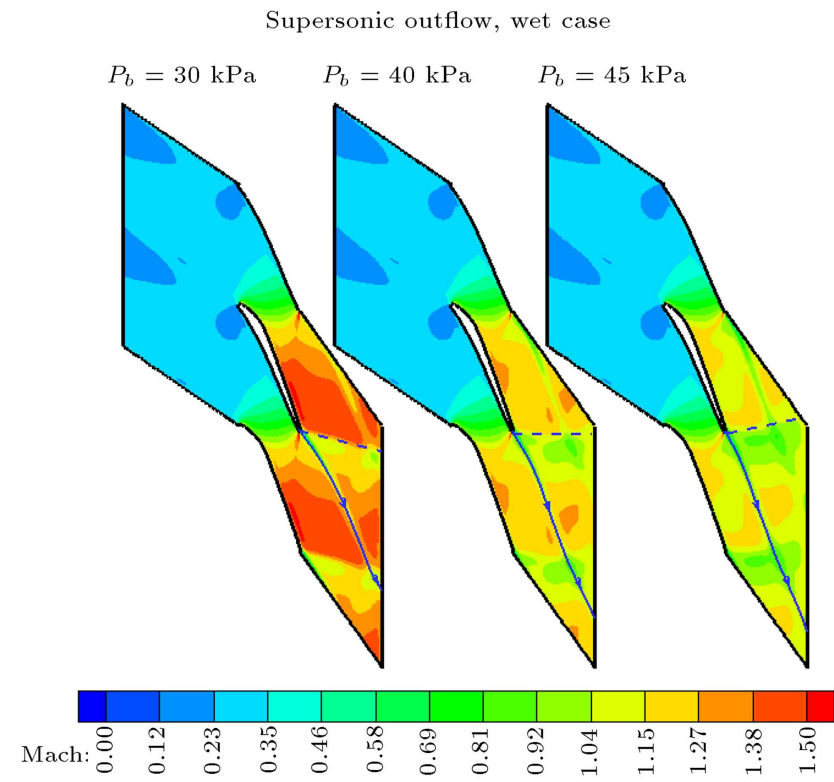

Figure 13. Representation of oblique shock and streamline at the trailing edge for different supersonic outlet pressures.

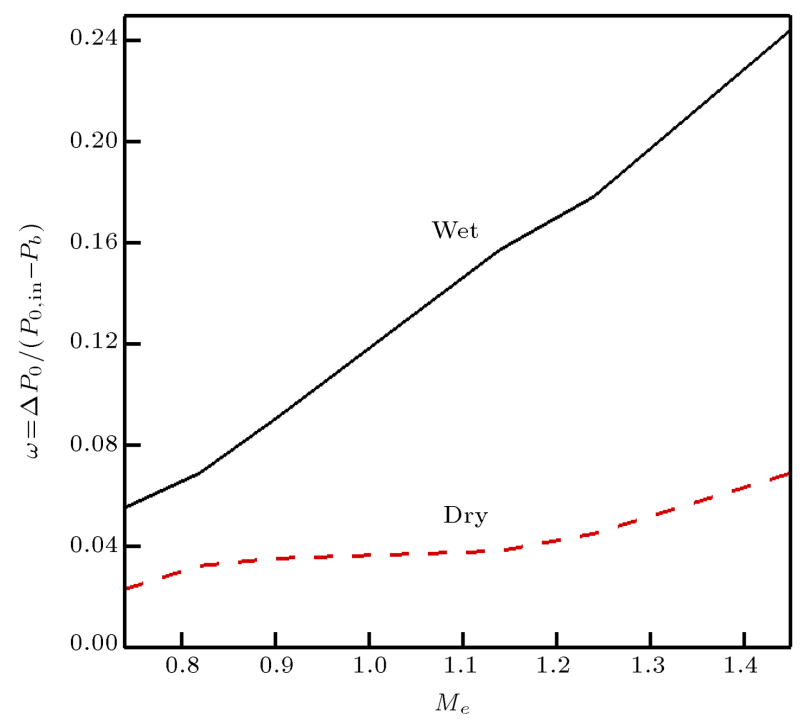

Figure 14. Variations of total pressure loss coefficient $(\omega)$ with exit Mach number $\left(M_{e}\right)$ for dry and wet cases.

$$
\begin{aligned}
& \omega=\frac{\left(P_{0}\right)_{\text {in }}-\left(P_{0}\right)_{e}}{\left(P_{0}\right)_{\text {in }}-(P)_{e}}=\frac{\Delta P_{0}}{\left(P_{0}\right)_{\text {in }}-(P)_{e}}, \\
& \dot{\sigma}=\bar{s}_{e}-\bar{s}_{i}
\end{aligned}
$$

where subscripts "in" and " $e$ " indicate inlet and exit sections, respectively.

Figures 14 and 15 plot the values of $\omega$ and $\dot{\sigma}$ as a function of exit Mach number $\left(M_{e}\right)$ for wet and dry cases. It can be seen that the values of $\omega$ and $\dot{\sigma}$ for wet case are larger than those in dry case; $\omega$ and $\dot{\sigma}$ also increase with $M_{e}$.

The prevailing feature in a non-equilibrium flow

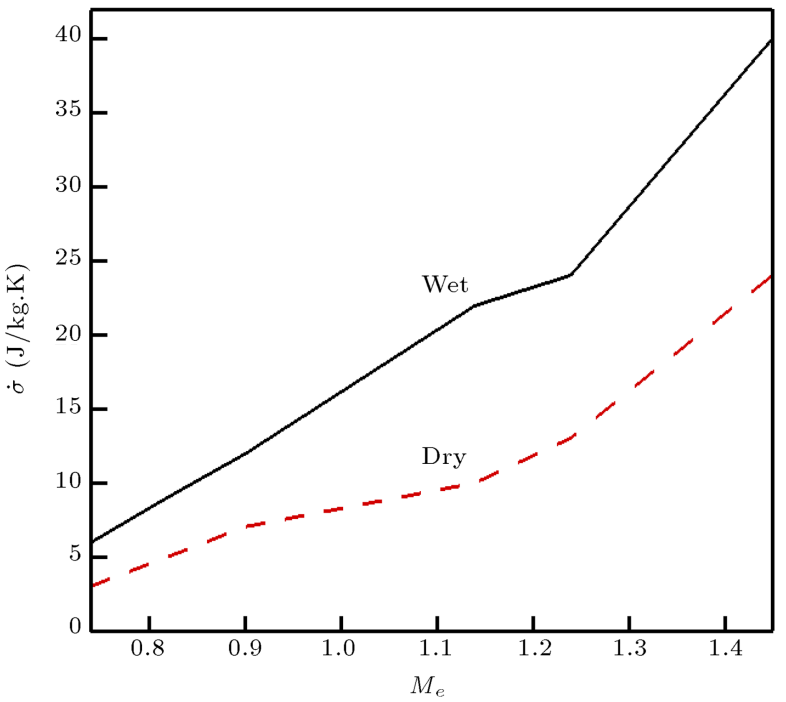

Figure 15. Variations of entropy generation $(\dot{\sigma})$ with exit Mach number $\left(M_{e}\right)$ for dry and wet cases.

is that the temperature of the phases differs. This difference in temperature is the source of irreversible heat transfer between phases. Subsequently, the entropy generation rate throughout the flow field becomes relatively substantial and is usually referred to as thermodynamic losses.

For wet case, there are thermodynamic losses in addition to aerodynamic losses of shock waves, and condensation shock is formed in the supersonic outflow cases. Thus, the values of $\omega$ and $\dot{\sigma}$ for wet case are larger than those in dry case. For example, according to Figures 14 and 15, it can be seen that for $M_{e}=1.45$, the values of $\omega$ and $\dot{\sigma}$ for wet case are, respectively, $254 \%$ and $67 \%$ more than those in dry case.

As observed in Figures 14 and 15, the values of $\omega$ and $\dot{\sigma}$ for supersonic outflow cases are more than subsonic cases due to higher value of thermodynamic losses and formation of the oblique shock in supersonic outflows. For example, due to the increase of $M_{e}$ from 0.9 to 1.45 , the values of $\omega$ and $\dot{\sigma}$ increase by $171 \%$ and $233 \%$, respectively, in wet case.

Figure 16 plots the values of deviation angle $\theta$ as a function of $M_{e}$ for dry and wet cases. As observed in this figure, the value of deviation angle for wet case is more than dry case. Also, the value of deviation angle increases with $M_{e}$. For instance, due to the increase of $M_{e}$ from 0.9 to 1.45 , the value of deviation angle increases by $408 \%$ in wet case. This is due to higher value of condensation rate and formation of oblique shock in the supersonic outflow case. As shown in Table 1 , due to increase of $M_{e}$ from 0.9 to 1.45 , the value of $\bar{\chi}_{e}$ (wetness fraction at exit plane) increases by $223 \%$. Thus, stagnation pressure loss on the suction surface for $M_{e}=1.45$ is more than $M_{e}=0.9$; hence, supersonic outflow cases have larger value of deviation angle in comparison with the subsonic cases. 
Table 1. Variations of exit wetness faction with back-pressure and exit Mach number for wet case.

\begin{tabular}{ccccccc}
\hline $\boldsymbol{P}_{\boldsymbol{b}}(\mathbf{k P a})$ & 70 & 65 & 60 & 45 & 40 & 30 \\
$\boldsymbol{M}_{\boldsymbol{e}}$ & 0.74 & 0.82 & 0.9 & 1.14 & 1.24 & 1.45 \\
$\begin{array}{c}\text { Flow regime } \\
\text { at exit plane }\end{array}$ & Subsonic & Subsonic & Subsonic & Supersonic & Supersonic & Supersonic \\
$(\bar{\chi})_{\boldsymbol{e}}$ & 0.006 & 0.009 & 0.013 & 0.025 & 0.031 & 0.042 \\
\hline
\end{tabular}

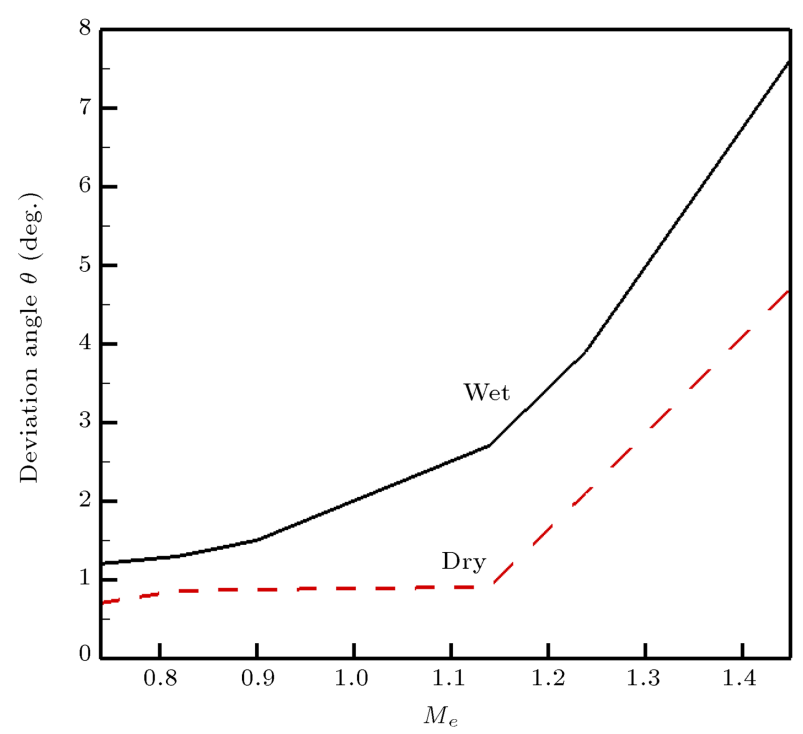

Figure 16. Variations of deviation angle $(\theta)$ with exit Mach number $\left(M_{e}\right)$ for dry and wet cases.

It is worthwhile to emphasize from practical point of view that as a result of condensation, the flow direction changes in the steam turbines, and consequently, the flow entering to the next blade deviates from its ondesign condition; thus, additional losses are produced. For example, the value of deviation angle reaches $7.62^{\circ}$ in wet case and $M_{e}=1.45$.

\section{Conclusions}

In this paper, an in-house CFD code has been developed using Roe scheme to study effects of condensation on flow field of the steam turbine rotor tip section for subsonic/supersonic flow regimes. Based on results of the paper, the following conclusions can be drawn:

- The suction surface has more expansion rate in comparison to the pressure surface. Thus, condensation rate and wetness fraction near the suction surface are more than those near the pressure surface;

- For supersonic outflow cases, decrease in the oblique shock angle and increase in the divergence angle of the trailing edge streamline are the two mechanisms for adapting the outlet pressure reduction;

- For supersonic outflow cases, total pressure loss coefficient, entropy generation, and deviation angle

are more than the subsonic cases. That is due to higher value of condensation rate and formation of oblique shock in the supersonic outflows;

- Condensation shock has two important effects on the flow field. Firstly, it increases the pressure and temperature of the flow. Also, condensation shock changes the oblique shock angle formed at the trailing edge. Thus, this phenomenon can affect downstream aerodynamics of the flow field;

- As a result of condensation, the aerothermodymics of the flow field changes. It changes the outflow direction from its on-design condition and causes the flow to enter to the next blade to deviate from its on-design condition, hence, produces additional losses. This subject should be considered in the design process of the blades after the nucleation zone in the steam turbines.

Also, there are stagnation pressure loss and entropy generation due to non-equilibrium condensation that reduce the overall efficiency of the steam turbine.

\section{Nomenclature}

$A$

C

$c_{p}$

$C_{P}$

$e_{t}$

$F$

$F_{1}$

G

$G_{1}$

$H_{t}$

$h_{f g}$

$J$

$\mathrm{J}$

$k_{B}$

$M$

$m_{v}$

$N$
Area

Chord length

Specific heat capacity at constant pressure

Pressure coefficient

Total internal energy per unit volume

Horizontal flux vector

Inviscid flux vector in $\xi$ direction

Vertical flux vector

Inviscid flux vector in $\eta$ direction

Total enthalpy

Latent heat of evaporation

Jacobian of transformation

New condensed droplets per unit volume and per second

Boltzmann constant

Mach number

Molecular weight of the vapor

Total number of droplets per unit mass of mixture 


\begin{tabular}{|c|c|}
\hline$p$ & Pitch length \\
\hline$P$ & Static pressure \\
\hline$P_{0}$ & Stagnation pressure \\
\hline$\left(P_{0}\right)_{e, p}$ & $\begin{array}{l}\text { Stagnation pressure at trailing edge } \\
\text { near the pressure surface }\end{array}$ \\
\hline$\left(P_{0}\right)_{e, s}$ & $\begin{array}{l}\text { Stagnation pressure at trailing edge } \\
\text { near the suction surface }\end{array}$ \\
\hline$P_{b}$ & Back-pressure \\
\hline$P_{s}$ & Saturation pressure \\
\hline$q$ & Either of the primitive variables \\
\hline$Q_{0}, Q_{1}, Q_{2}$ & Hill's moments \\
\hline$r$ & Average radius of droplets \\
\hline$r_{c}$ & Critical radius of droplets \\
\hline$R_{v}$ & Vapor constant (461.4 J/kg.K) \\
\hline$s$ & Entropy of the mixture \\
\hline$S$ & Source term \\
\hline$t$ & Time \\
\hline$T$ & Eigenvector \\
\hline$T_{l}$ & Droplet temperature \\
\hline$T_{S}$ & Saturation temperature \\
\hline$u, v$ & Velocity components \\
\hline$W$ & Conservative vector \\
\hline$x, y$ & Cartesian coordinates \\
\hline$\beta$ & Inflow direction \\
\hline$\gamma$ & Specific heat ratio of the vapor \\
\hline$\Gamma$ & Stagger angle \\
\hline$\rho$ & Mixture density \\
\hline$\sigma$ & Surface tension \\
\hline$\dot{\sigma}$ & Entropy generation \\
\hline$\theta$ & Deviation angle \\
\hline$\omega$ & Total pressure loss coefficient \\
\hline$\delta w$ & Wave amplitude vector \\
\hline$\phi$ & Correction parameter \\
\hline$\lambda$ & Eigenvalue of the flux Jacobian matrix \\
\hline$\chi$ & Wetness fraction \\
\hline$\xi, \eta$ & Curvilinear coordinates \\
\hline
\end{tabular}

\section{Subscripts}

$\begin{array}{ll}\text { in } & \text { Inlet section } \\ e & \text { Exit section } \\ l & \text { Liquid phase } \\ v & \text { Vapor phase } \\ S & \text { Saturation }\end{array}$

\section{References}

1. Gerbar, A.G. and Kermani, M.J. "A pressure based Eulerian-Eulerian multi-phase model for nonequilibrium condensation in transonic steam flow",
International Journal of Heat and Mass Transfer, 47(10), pp. 2217-2231 (2004).

2. Baumann, K. "Some recent developments in large steam turbine practice", Journal of the Institute of Electrical Engineers, 59, pp. 565-570 (1921).

3. Mcdonald, J.E. "Homogeneous nucleating of vapor condensation I \& II, Kinetic \& Thermodynamic aspects", American Journal of Physics, 30(870), pp. 870877 (1962).

4. Moore, M.J., Walters, P.T. and Crane, R.I. "Predicting the fog-drop size in wet steam turbines", International Mechanical Engineering Conference, Warwick (1973).

5. Skillings, S.A. "Condensation phenomena in a turbine blade passage", Journal of Fluid Mechanics, 200, pp. 409-424 (1989).

6. Skillings, S.A. "An analysis of the condensation phenomena occurring in wet steam turbines", PhD Thesis, CNAA, CERL (1987).

7. Bakhtar, F. and Mahpeykar, M.R. "On the performance of a cascade of turbine rotor tip section blading in nucleating steam, Part 3: Theoretical treatment", Proceedings of the Institution of Mechanical Engineers, 211(3), pp. 195-210 (1997).

8. Bakhtar, F., Mamat, Z.A. and Jadayel, O.C. "On the performance of a cascade of improved turbine nozzle blades in nucleating steam. Part 1: Surface pressure distributions", Proc. IMechE, Part C: Journal of Mechanical Engineering Science, 223(8), pp. 19031914 (2009).

9. Bakhtar, F., Mamat, Z.A. and Jadayel, O. C. "On the performance of a cascade of improved turbine nozzle blades in nucleating steam. Part 2: Wake traverses", Proc. IMechE, Part C: Journal of Mechanical Engineering Science, 223(8), pp. 1915-1929 (2009).

10. Bakhtar, F., Zamri, M.Y. and Rodriguez-Lelis, J.M. "A comparative study of treatment of two-dimensional two-phase flows of steam by a Runge-Kutta and by Denton's methods", Proc. IMechE, Part C: Journal of Mechanical Engineering Science, 221(6), pp. 689-706 (2007).

11. Young, J.B. "Critical conditions and the chocking mass flow rate in non-equilibrium wet steam flows", Journal of Fluids Engineering, 106(4), pp. 452-458 (1984).

12. Young, J.B. "Two-dimensional, non-equilibrium, wetsteam calculations for nozzles and turbine cascades", Journal of Turbomachinery, 114, pp. 569-579 (1992).

13. White, A.J. and Young, J.B. "Time-marching method for the prediction of two-dimensional unsteady flows of condensing steam", Journal of Propulsion and Power, 9(2), pp. 579-587 (1993).

14. White, A.J. "Numerical investigation of condensing steam flow in boundary layers", International Journal of Heat and Fluid Flow, 21(6), pp. 727-734 (2000). 
15. White, A.J. and Hounslow, M.J. "Modeling droplet size distributions in polydispersed wet-steam flows", International Journal of Heat and Mass Transfer, 43(11), pp. 1873-1884 (2000).

16. White, A.J. "A comparison of modeling methods for polydispersed wet-steam flow", International Journal for Numerical Methods in Engineering, 57(6), pp. 819834 (2003).

17. Gerber, A.G. "Two-phase eulerian/lagrangian model for nucleating steam flow", Journal of Fluids Engineering, 124(2), pp. 465-475 (2002).

18. Gerber, A.G. and Mousavi, A. "Application of quadrature method of moments to the polydispersed droplet spectrum in transonic steam flows with primary and secondary nucleation", Applied Mathematical Modelling, 31(8), pp. 1518-1533 (2007).

19. Halama, J., Benkhaldoun, F. and Fort, J. "Numerical modeling of two-phase transonic flow", Mathematics and Computers in Simulation, 80(8), pp. 1624-1635 (2010).

20. Dykas, S. and Wroblewki, W. "Single- and two-fluid models for steam condensing flow modeling", International Journal of Multiphase Flow, 37(9), pp. 12451253 (2011).

21. Dykas, S. and Wroblewki, W. "Numerical modeling of steam condensing flow in low and high-pressure nozzles", International Journal of Heat and Mass Transfer, 55(21), pp. 6191-6199 (2012).

22. Hamidi, S. and Kermani, M.J. "Numerical solution of compressible two-phase moist-air flow with shocks", European Journal of Mechanics - B/Fluids, 42, pp. 20-29 (2013).

23. Bagheri-Esfe, H., Kermani, M.J. and Saffar-Avval, M. "Effects of non-equilibrium condensation on deviation angle and efficiency in a steam turbine stage", Journal of Mechanical Science and Technology, 30(3), pp. 1-11 (2016).

24. Bagheri-Esfe, H., Kermani, M.J. and Saffar-Avval, M. "Effects of surface roughness on deviation angle and performance losses in wet steam turbines", Applied Thermal Engineering, 90, pp. 158-173 (2015).

25. Halama, J., Dobe, J., Fort, J. and Kozel, K. "Numerical modeling of unsteady flow in steam turbine stage", Journal of Computational and Applied Mathematics, 234(7), pp. 2336-2341 (2010).

26. Hill, P.G. "Condensation of water vapor during supersonic expansion in nozzles", Journal of Fluid Mechanics, 25(03), pp. 593-620 (1966).

27. Kermani, M.J. and Gerber, A.G. "A general formula for the evaluation of thermodynamic and aerodynamic losses in nucleating steam flow", International Journal of Heat and Mass Transfer, 46(17), pp. 3265-3278 (2003).

28. Sislian, J.P. "Condensation of water vapour with or without a carrier gas in a shock tube", UTIAS Report No. 201, Toronto University (1975).
29. Anderson, J., Computational Fluid Dynamics; The Basics with Applications, McGraw-Hill, New York, USA (1995).

30. Van Leer, B. "Towards the ultimate conservation difference scheme, V, A second order sequel to Godunov's method", Journal of Computational Physics, 32(1), pp. 110-136 (1979).

31. Kermani, M.J. and Plett, E.G. "Roe scheme in generalized coordinates: Part I- Formulations", AIAA Journal, 0086, pp. 86-92 (2001).

32. Kermani, M.J. and Plett, E.G. "Modified entropy correction formula for the Roe scheme", AIAA Journal, 0083, pp. 83-88 (2001).

33. Kermani, M.J. "Development and assessment of upwind schemes with application to inviscid and viscous flows on structured meshes", PhD Thesis, Department of Mechanical \& Aerospace Engineering, Carleton University, Canada (2001).

34. Bakhtar, F., Ebrahimi, M. and Webb, R.A. "On the performance of a cascade of turbine rotor tip section blading in nucleating steam, Part 1: Surface pressure distributions", Proc. IMechE, Part C: Journal of Mechanical Engineering Science, 209(2), pp. 115124 (1995).

35. John, J., Gas Dynamics, Allyn and Bacon, Boston (1969).

\section{Biographies}

Hamed Bagheri-Esfe is currently an Assistant Professor in Mechanical Engineering group in Shahreza University, Shahreza, Iran. He completed his BSc in Mechanical Engineering (Thermal-Fluid) from the Kashan University, his MS in Mechanical Engineering from the Birjand University (1st rank), and his PhD degree from the Amitkabir University of Technology. For his PhD program, he worked on effects of nonequilibrium condensation in steam turbines. His fields of interest include computational fluid dynamics, compressible flows, and two-phase flows.

Mohammad Jafar Kermani is an Associate Professor in the Amirkabir University of Technology. He completed his BSc in Mechanical Engineering (ThermalFluid) from Shiraz University (2nd rank), his MS in Applied Mathematics from Manchester University (1st rank), and his $\mathrm{PhD}$ from Carleton University. Then, he pursued a two-year postdoctoral fellowship in the University of New Brunswick, Canada on steam turbines and proton exchange membrane fuel cells. He has written over 100 papers and has supervised more than 70 students.

Majid Saffar-Avval is a Professor of Mechanical Engineering in Amirkabir University of Technology (AUT), Tehran, Iran. He received his BSc and MSc 
degrees from Sharif University of Technology, and his $\mathrm{PhD}$ degree from the Ecole Nationale des Arts et Metiers (ENSAM), Paris, France, in 1985. He has been teaching at the AUT since then. He was the head of the Mechanical Engineering Department from June 2000 to
June 2002 and head of the Energy and Control Center of Excellence from May 2007 to March 2012 at AUT. His research contributions are in the field of two-phase heat transfer, advanced thermal systems, and energy management. 